\title{
Phase II study of neoadjuvant imatinib in large gastrointestinal stromal tumours of the stomach
}

Yukinori Kurokawa*,1, Han-Kwang Yang ${ }^{\star}, 2$, Haruhiko Cho $^{3}$, Min-Hee Ryu ${ }^{4}$, Toru Masuzawa ${ }^{5}$, Sook Ryun Park ${ }^{4}$, Sohei Matsumoto ${ }^{6}$, Hyuk-Joon Lee ${ }^{2}$, Hiroshi Honda ${ }^{7}$, Oh Kyoung Kwon ${ }^{8}$, Takashi Ishikawa ${ }^{9}$, Kyung Hee Lee ${ }^{10}$, Kazuhito Nabeshima ${ }^{11}$, Seong-Ho Kong ${ }^{2}$, Toshio Shimokawa ${ }^{12}$, Jeong-Hwan Yook ${ }^{13}$, Yuichiro Doki ${ }^{1}$, Seock-Ah $\mathrm{Im}^{14}$, Seiichi Hirota ${ }^{15}$, Seokyung Hahn ${ }^{16}$, Toshirou Nishida ${ }^{17}$ and Yoon-Koo Kang ${ }^{4}$

${ }^{1}$ Department of Gastroenterological Surgery, Osaka University Graduate School of Medicine, 2-2, Yamadaoka, Suita, Osaka 565-0871, Japan; ${ }^{2}$ Department of Surgery and Cancer Research Institute, Seoul National University College of Medicine, 101 Daehak-Ro, Jongno-gu, Seoul 03080, South Korea; ${ }^{3}$ Department of Surgery, Kanagawa Cancer Center, 2-3-2 Nakao, Asahi-ku, Yokohama 241-8515, Japan; ${ }^{4}$ Department of Oncology, Asan Medical Center, University of Ulsan College of Medicine, 88 Olympic-ro 43-gil, Seoul 05505, South Korea; ${ }^{5}$ Department of Surgery, Osaka Police Hospital, 10-31, Kitayamacho, Tennoji-ku, Osaka 543-0035, Japan; ${ }^{6}$ Department of Surgery, Nara Medical University, 840 Shijo-cho, Kashihara, Nara 634-8522, Japan; 'Department of Surgery, Sendai Open Hospital, 5-221, Tsurugaya, Miyagino-ku, Sendai 983-0824, Japan; ${ }^{8}$ Gastric Cancer Center, Kyungpook National University Medical Center, 807 Hoguk-ro, Buk-gu, Daegu 41404, South Korea; ${ }^{9}$ Department of Surgery, Niigata University, 1-754, Asahimachidouri, Niigata 951-8520, Japan; ${ }^{10}$ Departments of Hemato-oncology, Yeungnam Medical Center, 170, Hyeonchung-ro, Nam-gu, Daegu 42415, South Korea; ${ }^{11}$ Department of Surgery, Tokai University, 143, Shimokasuya, Isehara 259-1193, Japan; ${ }^{12}$ Clinical Study Support Center, Wakayama Medical University, 811-1, Kimiidera, Wakayama 641-8510, Japan; ${ }^{13}$ Department of Surgery, Asan Medical Center, University of Ulsan College of Medicine, 88 Olympic-ro 43-gil, Seoul 05505, South Korea; ${ }^{14}$ Department of Internal Medicine and Cancer Research Institute, Seoul National University College of Medicine, 101 Daehak-Ro, Jongno-gu, Seoul 03080, South Korea; ${ }^{15}$ Department of Surgical Pathology, Hyogo College of Medicine, 1-1, Mukogawacho, Nishinomiya 663-8501, Japan; ${ }^{16}$ Medical Research Collaborating Center, Seoul National University Hospital, 101 Daehak-Ro, Jongno-gu, Seoul 03080, South Korea and ${ }^{17}$ National Cancer Center Hospital, 5-1-1, Tsukiji, Chuo-ku, Tokyo 104-0045, Japan

Background: Gastrointestinal stromal tumours (GISTs) with high-risk features have poor prognosis even if adjuvant treatment is given. Neoadjuvant imatinib may increase the cure rate by shrinking large GISTs and preserve organ function.

Methods: We conducted an Asian multinational phase II study for patients with gastric GISTs $\geq 10 \mathrm{~cm}$. Patients received neoadjuvant imatinib (400 mg/day) for 6-9 months. The primary end point was RO resection rate.

Results: A total of 56 patients were enroled in this study. In the full analysis set of 53 patients, neoadjuvant imatinib for $\geq 6$ months was completed in 46 patients. Grade 3-4 neutropenia and rash occurred in $8 \%$ and $9 \%$, respectively, but there were no treatmentrelated deaths. The response rate by RECIST was $62 \%$ (95\% Cl, 48-75\%). The R0 resection rate was 91\% (48/53) (95\% Cl, 79-97\%). Preservation of at least half of the stomach was achieved in 42 of 48 patients with RO resection. At the median follow-up time of 32 months, 2-year overall and progression-free survival rates were $98 \%$ and $89 \%$, respectively.

Conclusions: Neoadjuvant imatinib treatment for 6-9 months is a promising treatment for large gastric GISTs, allowing a high RO resection rate with acceptable toxicity.

*Correspondence: Y Kurokawa; E-mail: ykurokawa@gesurg.med.osaka-u.ac.jp or H-K Yang; E-mail: hkyang@snu.ac.kr 
Gastrointestinal stromal tumour (GIST) is the most common mesenchymal tumour in the gastrointestinal tract, with the majority originating in the stomach (Miettinen and Lasota, 2006a). Surgical resection is the only curative treatment for GIST. Independent prognostic factors for recurrence after resection include tumour size, mitotic count, tumour location, and tumour rupture. GISTs with high-risk features such as large tumour size, high mitotic count, or tumour rupture have poor prognosis after resection (Joensuu, 2008); more than half of the patients with such tumours suffer from recurrence within 5 years after surgery (Joensuu et al, 2012). For such high-risk cases, adjuvant treatment has been attempted to reduce recurrence rate.

GISTs usually demonstrate activating mutations in either KIT or platelet-derived growth factor receptor alpha (PDGFRA) (Rubin et al, 2007). Imatinib, a tyrosine kinase inhibitor of KIT protein, is highly effective against GISTs. A small subset of patients with metastatic GIST may achieve durable complete remission on imatinib. Two phase III studies comparing adjuvant imatinib with surgery alone have been conducted in intermediate- and high-risk GIST patients (Dematteo et al, 2009; Corless et al, 2014; Casali et al, 2015). Both studies demonstrated that adjuvant imatinib prolonged recurrence-free survival, but eventually many patients showed recurrence after termination of adjuvant imatinib. Neoadjuvant imatinib treatment may shrink tumour size remarkably and prevent tumour rupture during surgery, leading to increased proportions of 'true' complete resection. Furthermore, neoadjuvant treatment may produce secondary advantages in terms of preserving organ function. For the patients with stomach tumours, complete gastrectomy should be avoided wherever possible due to the significant morbidity associated (Robertson et al, 1994).

Several retrospective case series and a very small-scale $(n=14)$ prospective study have assessed the feasibility of neoadjuvant imatinib (Sjölund et al, 2010; Doyon et al, 2012; Tirumani et al, 2014). In addition, one phase II study (RTOG0132) of 8-12 weeks neoadjuvant imatinib for GISTs of $5 \mathrm{~cm}$ or larger and another phase II study (APOLLON) of 6 months neoadjuvant imatinib for potentially resectable GISTs showed R0 resection rates of $68 \%$ (21/ 31 ) and $71 \%$ (32/45), respectively (Hohenberger et al, 2012; Wang et al, 2012). As these studies included heterogeneous tumour characteristics (size, risk classification, tumour location), it was difficult to evaluate of the efficacy of neoadjuvant imatinib. We therefore designed this multinational phase II study to investigate the efficacy and safety of neoadjuvant imatinib for 6-9 months only in patients with large $(\geq 10 \mathrm{~cm})$ gastric GISTs.

\section{PATIENTS AND METHODS}

Study design and patients. This study was a phase II, single group, non-randomised study conducted at 25 institutions in Japan and South Korea. We enroled patients with histologically proven primary GISTs located in the stomach. The tumour diameter was required to be $10 \mathrm{~cm}$ or larger as identified by abdominal enhanced CT scan. Patients were required to have neither apparent distant metastasis nor peritoneal metastasis. Eligibility criteria also included: age 20-79 years; Eastern Cooperative Oncology Group performance status score of 0 or 1 ; no previous treatment for the disease, including surgery, chemotherapy, and radiotherapy; adequate oral intake; and adequate organ function. Patients provided written informed consent before enrolment. The study protocol was approved by the institutional review boards of all participating hospitals. This study is registered with UMIN Clinical Trials Registry, number UMIN000003114.

Treatment. After registration, patients received oral imatinib ( $400 \mathrm{mg}$ /day) once a day for 6 months ( 24 weeks) as a neoadjuvant treatment. If the tumour response was defined as progressive disease at 1 or 3 months after starting the administration, the protocol treatment was discontinued. If the tumour response was defined as complete response (CR) or partial response (PR) at 6 months after starting the administration, the neoadjuvant imatinib could be continued until 9 months (36 weeks).

Surgery was performed within 1 month of final evaluation of neoadjuvant treatment, and treatment was finally discontinued within 1 week of surgery. Surgical procedures and reconstruction methods were not prescribed by the study protocol, but as a rule R0 (macroscopically and histologically negative margin) resection was the intention. When R1 (histologically positive margin or tumour rupture) or R2 (macroscopically residual tumour) resection was performed, any treatments including continuation of imatinib were allowed after surgery.

After R0 resection, patients received imatinib (400 mg/day) once a day for at least 1 year. If the dose of preoperative neoadjuvant imatinib was reduced to $300 \mathrm{mg} /$ day, the postoperative dose was to be started at $300 \mathrm{mg} /$ day. Regardless of the efficacy of neoadjuvant imatinib, postoperative imatinib was begun within 7 days after subjects started to take food orally. The protocol treatment was discontinued if imatinib could not be started within 3 months after surgery due to surgical complications or other reasons.

Assessments. The primary end point was the R0 resection rate, and the secondary end points were overall survival, progressionfree survival, objective response rate, pathological response rate (only in Japan), stomach preservation rate, treatment completion rate, incidence of adverse events, and imatinib plasma levels. Tumour responses were evaluated in accordance with both the RECIST (version 1.1) and Choi criteria by abdominal enhanced CT at weeks 4,12 , and 24 after starting neoadjuvant imatinib (Choi et al, 2007; Eisenhauer et al, 2009). Confirmation of CR or PR was not needed in this study. These evaluations were performed by physicians and radiologists at each institution. Adverse events were evaluated according to the National Cancer Institute Common Terminology Criteria for Adverse Events, version 3.0. After surgery, the presence or absence of recurrence was evaluated by abdominal enhanced CT every 3 months for the first 2 years after surgery and every 6 months for the subsequent 3 years.

Genotyping was carried out using biopsy specimens obtained before neoadjuvant imatinib or surgically resected specimens obtained after neoadjuvant imatinib. Whole-coding regions of KIT and PDGFRA cDNAs or selected regions of KIT genomic DNA (exons 9, 11, 13, 17) and PDGFRA genomic DNA (exons 12, 14, 18) were sequenced as previously described (Hirota et al, 1998; Hirota et al, 2003).

Statistical analysis. Based on the R0 resection rate of $68 \%(21 / 31)$ in the RTOG0132 study (Wang et al, 2012), the required sample size was estimated with a threshold $\mathrm{R} 0$ resection rate of $70 \%$ and an expected R0 resection rate of $85 \%$, power of $80 \%$, and a one-sided significant level of 0.05 using the binomial test. Given 10\% ineligible patients, the target sample size was determined to be 55 patients.

The primary outcome was analysed with a one-sample binomial test. For secondary outcomes, we estimated response rates and $95 \%$ confidence intervals (CIs) using the Clopper-Pearson exact method. For overall and progression-free survival, we used the Kaplan-Meier method to estimate survival curves and Greenwood's formula to calculate 95\% CIs for survival rates. All the analyses were conducted with $\mathrm{R}$, version 3.2.2.

The full analysis set (FAS) was defined as the eligible patients who started neoadjuvant imatinib. The R0 resection rate was calculated using the number of patients in the FAS as the denominator and the number of patients who underwent R0 resection as the numerator. The stomach preservation rate was calculated using the FAS count as the denominator and the 
number of the patients who underwent R0 resection and who preserved at least half of the stomach as the numerator. Completion of neoadjuvant imatinib was not considered in the estimation of $\mathrm{R} 0$ resection rate or stomach preservation rate. Overall survival was defined as the time from the date of enrolment to the date of death from any cause. Progression-free survival was defined as the time from the date of enrolment to the date of disease progression, R1/2 resection, recurrence after surgery, or death from any cause. For patients who refused to undergo surgery, progression-free survival was not censored and was followed until disease progression.

\section{RESULTS}

Patient background. Between February 2010 and September 2014, a total of 56 patients were enroled (Figure 1). Two patients were ineligible, and one patient did not start neoadjuvant imatinib because mutation analysis of the biopsy specimen revealed PDGFRA exon 18 D842V mutation. Efficacy and safety analyses of neoadjuvant imatinib were therefore conducted in the FAS of the remaining 53 patients. The characteristics of these 53 patients are listed in Table 1. Sixty percent of patients were from Japan, and the rest were from South Korea. The median tumour size was $12.0 \mathrm{~cm}$ (range, $10.0-23.0 \mathrm{~cm}$; interquartile range (IQR), $10.4-15.7 \mathrm{~cm}$ ). Genotyping of biopsy and/or surgical specimens showed KIT exon 11 mutation in 47 patients and wild-type KIT and PDGFRA in two patients. Samples from four patients were not available or suitable for the analysis.

Feasibility. In total, 46 of 53 patients (87\%) completed at least 6 months (24 weeks) of neoadjuvant imatinib therapy. Dose reduction of imatinib during neoadjuvant treatment was required in 14 patients (26\%). The reasons of dose reduction were nonhaematological toxicity for 10 patients, haematological toxicity for three patients, and other (high imatinib plasma trough level) for one patient. The median duration of neoadjuvant imatinib administration in the FAS was 26.0 weeks (range, 1.7-39.6 weeks; IQR, 24.0-35.9 weeks). All adverse events experienced during neoadjuvant imatinib treatment are shown in Table 2. The most common non-haematological toxicities were oedema of the head and neck (any grade, 72\%) followed by rash (any grade, $45 \%$ ). Grade 3-4 neutropenia and rash occurred in $8 \%$ and $9 \%$ of patients, respectively. Grade 4 cerebrovascular ischaemia occurred in one patient, and there were no treatment-related deaths. Seven patients discontinued neoadjuvant imatinib due to adverse events ( 2 rash, 2 interstitial pneumonitis, 2 fever, 1 cerebrovascular ischaemia). In the 46 patients who completed at least 6 months of neoadjuvant imatinib treatment, the mean \pm s.d. of imatinib plasma trough level at 6 months after starting neoadjuvant imatinib was $1852 \pm 1572 \mathrm{ng} / \mathrm{ml}$ (range, 436 to $9660 \mathrm{ng} / \mathrm{ml}$ ) (one missing value).

Efficacy. A waterfall plot representing the ranked best tumour shrinkage after neoadjuvant imatinib is shown in Figure 2. The median shrinkage rate in the 53 patients was $35.4 \%$ (range, $0.0-87.0 \%$ ), and neoadjuvant imatinib brought favourable shrinkage of tumour even in two patients with wild-type GIST $(40.8 \%$ and $50.5 \%$ ). The objective best response rate and the disease control rate evaluated by RECIST in the FAS were 62\% (95\% CI, $48-75 \%$ ) and $100 \%$ (95\% CI, 93-100\%), respectively. The objective best response rate and the disease control rate evaluated by the Choi criteria in the FAS were 98\% (95\% CI, 90-100\%) and 100\% (95\% CI, 93-100\%), respectively. Of the 46 patients who completed

\begin{tabular}{|c|c|}
\hline & $(n=53)$ \\
\hline \multicolumn{2}{|l|}{ Country } \\
\hline Japan & $32(60 \%)$ \\
\hline Korea & $21(40 \%)$ \\
\hline \multicolumn{2}{|l|}{ Age (years) } \\
\hline Median & 69 \\
\hline Range & $43-79$ \\
\hline IQR & $62-73$ \\
\hline \multicolumn{2}{|l|}{ Sex } \\
\hline Male & $24(45 \%)$ \\
\hline Female & $29(55 \%)$ \\
\hline \multicolumn{2}{|l|}{ ECOG performance status } \\
\hline 0 & $28(53 \%)$ \\
\hline 1 & 25 (47\%) \\
\hline \multicolumn{2}{|l|}{ Tumour size $(\mathrm{cm})$} \\
\hline Median & 12.0 \\
\hline Range & $10.0-23.0$ \\
\hline IQR & $10.4-15.7$ \\
\hline \multicolumn{2}{|c|}{ Sampling method used to obtain tumour tissue } \\
\hline Endoscopic standard biopsy & 24 \\
\hline EUS-FNA & 28 \\
\hline Percutaneous biopsy & 1 \\
\hline \multicolumn{2}{|l|}{ Genotyping } \\
\hline KIT exon 11 & 47 (89\%) \\
\hline Wild-type KIT and PDGFRA & 2 (4\%) \\
\hline Not available & 4 (8\%) \\
\hline \multicolumn{2}{|c|}{$\begin{array}{l}\text { Abbreviations: } I Q R=\text { interquartile range; } E C O G=\text { Eastern Cooperative Oncology Group; } \\
\text { EUS-FNA = endoscopic ultrasound-guided fine-needle aspiration. }\end{array}$} \\
\hline
\end{tabular}

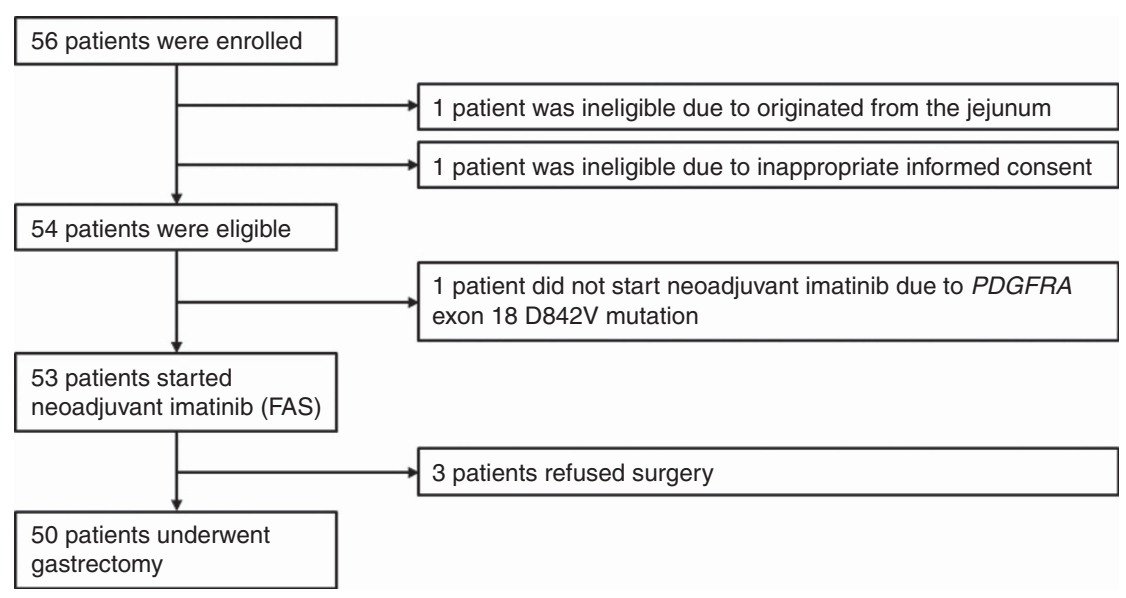

Figure 1. Study profile. FAS, full analysis set; PDGFRA, platelet-derived growth factor receptor alpha. 
Table 2. Adverse events during neoadjuvant imatinib treatment $(n=53)$

\section{No. of patients (\%)}

\begin{tabular}{|c|c|c|c|c|c|c|}
\hline Events & Grade 1 & Grade 2 & Grade 3 & Grade 4 & All grade & Grade 3-4 \\
\hline Neutropenia & $16(30 \%)$ & 18 (34\%) & $2(4 \%)$ & $2(4 \%)$ & 38 (72\%) & $4(8 \%)$ \\
\hline Leukopenia & $9(17 \%)$ & $16(30 \%)$ & $2(4 \%)$ & 0 & 27 (51\%) & $2(4 \%)$ \\
\hline Anaemia & 29 (55\%) & $20(38 \%)$ & $1(2 \%)$ & 0 & $50(94 \%)$ & $1(2 \%)$ \\
\hline AST & $15(28 \%)$ & 0 & 0 & 0 & $15(28 \%)$ & 0 \\
\hline ALT & $14(26 \%)$ & $1(2 \%)$ & 0 & 0 & $15(28 \%)$ & 0 \\
\hline Creatinine & $9(17 \%)$ & 0 & 0 & 0 & $9(17 \%)$ & 0 \\
\hline Rash & $11(21 \%)$ & $8(15 \%)$ & $5(9 \%)$ & 0 & $24(45 \%)$ & $5(9 \%)$ \\
\hline Oedema (limb) & 20 (38\%) & $1(2 \%)$ & 0 & 0 & $21(40 \%)$ & 0 \\
\hline Anorexia & $13(25 \%)$ & $3(6 \%)$ & 0 & 0 & $16(30 \%)$ & 0 \\
\hline Nausea & $13(25 \%)$ & $3(6 \%)$ & 0 & 0 & $16(30 \%)$ & 0 \\
\hline Vomiting & $10(19 \%)$ & $2(4 \%)$ & $1(2 \%)$ & 0 & $13(25 \%)$ & $1(2 \%)$ \\
\hline Fever & $1(2 \%)$ & $1(2 \%)$ & 0 & 0 & $2(4 \%)$ & 0 \\
\hline Mucositis & $2(4 \%)$ & 0 & 0 & 0 & $2(4 \%)$ & 0 \\
\hline Febrile neutropenia & 0 & 0 & $1(2 \%)$ & 0 & $1(2 \%)$ & $1(2 \%)$ \\
\hline Hypoxia & 0 & 0 & $1(2 \%)$ & 0 & $1(2 \%)$ & $1(2 \%)$ \\
\hline CNS ischaemia & 0 & 0 & 0 & $1(2 \%)$ & $1(2 \%)$ & $1(2 \%)$ \\
\hline Dizziness & 0 & 0 & $1(2 \%)$ & 0 & $1(2 \%)$ & $1(2 \%)$ \\
\hline Pruritus & 0 & $1(2 \%)$ & 0 & 0 & $1(2 \%)$ & 0 \\
\hline
\end{tabular}

at least 6 months of neoadjuvant imatinib, the earliest point at which maximal reduction of tumour size was observed was 4 weeks after neoadjuvant imatinib initiation in 1 case (2\%), 12 weeks in 9 cases (20\%), 24 weeks in 29 (63\%) cases, and 36 weeks in $7(15 \%)$ cases.

Of the 53 patients who received neoadjuvant imatinib, 50 proceeded to surgery. Three patients refused to undergo surgery. The surgical data are summarised in Table 3. More than $80 \%$ of the patients underwent partial gastrectomy. A quarter of the patients underwent combined resection of other organs, excluding the gallbladder. There was one case with tumour rupture at surgery. R0 resection was achieved in 48 patients, $\mathrm{R} 1$ (tumour rupture) in one, and $\mathrm{R} 2$ in one. The $\mathrm{R} 0$ resection rate in the FAS (the primary end point) was $91 \%$ (95\% CI, 79-97\%). This was much higher than the pre-specified threshold of $70 \%$ (one-sided $P<0.001$ ). At least half of the stomach was preserved with R0 resection in $79 \%$ of cases (95\% CI, 66-89\%). Operative morbidities of any grade occurred in nine patients (two postoperative bleeding, two wound infection, two anastomotic leakage, one bowel obstruction, one intraabdominal infection, and one pyloric stenosis). There were no treatmentrelated or in-hospital deaths.

The pathological findings of 50 patients who underwent surgical resection are shown in Table 3 . The median postoperative tumour size was $8.0 \mathrm{~cm}$ (range, $4.7-20.0 \mathrm{~cm}$; IQR, $7.5-11.8 \mathrm{~cm}$ ). Peritoneal metastasis was observed in three patients $(6 \%)$, but there were no patients with lymph node metastasis. Of the 50 patients, $42(84 \%)$ had tumours with mitotic counts less than five per 50 high-power fields (HPF).

Of the 42 patients who underwent $\mathrm{R} 0$ resection after completion of at least 6 months of neoadjuvant imatinib therapy, 40 started adjuvant imatinib. One patient refused to receive imatinib after surgery, and the other patient could not take imatinib due to postoperative morbidity. As a result, 38 of 40 patients (95\%) continued adjuvant imatinib therapy at least during the first year after surgery. At the median follow-up of 32 months, the 2-year overall survival rate in the FAS was 98\% (95\% CI, 95-100\%; Figure $3 \mathrm{~A}$ ). The 2-year progression-free survival rate in the FAS was $89 \%$ (95\% CI, 81-98\%; Figure 3B). Of the 48 patients who underwent R0 resection, tumour recurrence occurred in seven patients. The sites of recurrence were the liver $(n=5)$, peritoneum $(n=2)$, and local $(n=2)$ (two patients had duplicated sites).

\section{DISCUSSION}

A previous phase III study (Z9001) proved that adjuvant imatinib treatment for 1 year significantly prolonged recurrence-free survival, but eventually $60 \%$ of patients with GISTs larger than $10 \mathrm{~cm}$ showed recurrence within 3 years (Dematteo et al, 2009). Another phase III study (EORTC62024) comparing 2-year adjuvant imatinib with surgery alone found that nearly half of high-risk GIST patients showed recurrence within 6 years even after 2-year adjuvant imatinib (Casali et al, 2015). These results may indicate that the strategy of adjuvant treatment is insufficient to cure patients with high-risk GISTs. Cure of GISTs can only be obtained by 'true' complete resection. However, neoadjuvant imatinib treatment may shrink tumour size remarkably and prevent tumour rupture during surgery, and thus lead to increased rates of complete resection. Indeed, the median shrinkage rate in this study was $35.4 \%$, and no patients showed growth of primary tumours while receiving neoadjuvant treatment. Furthermore, neoadjuvant imatinib could preserve the functioning of tumour-involved organs in many patients. Although our study included only large tumours (median, 


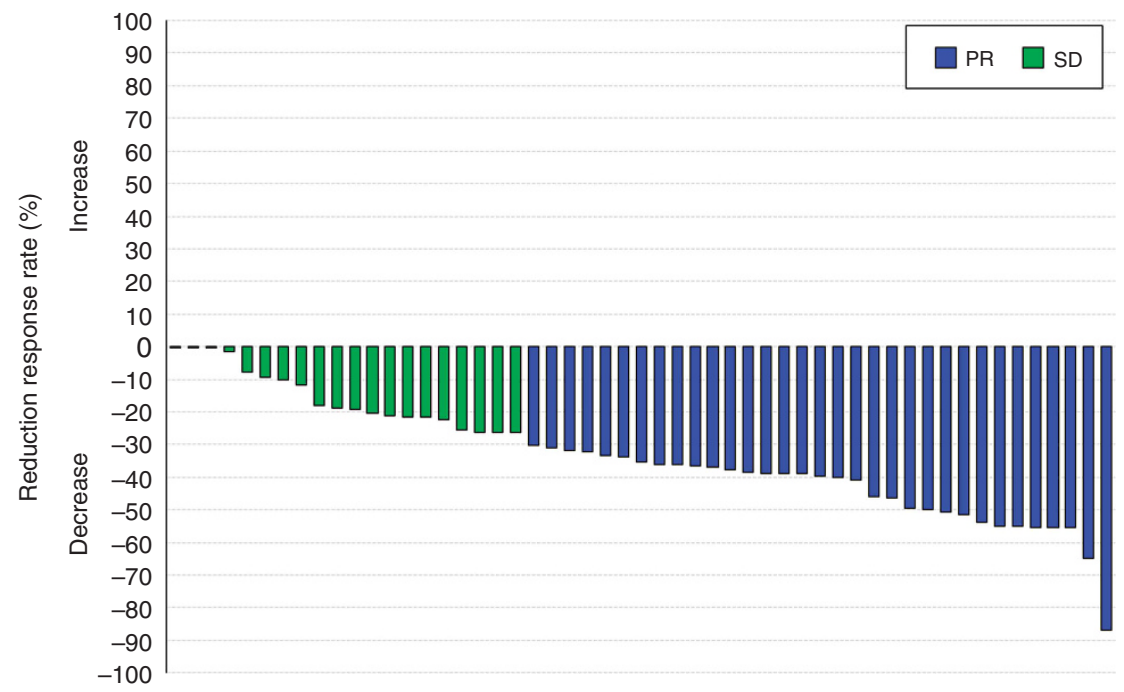

Figure 2. Waterfall plot of the ranked best tumour shrinkage after neoadjuvant imatinib.

Table 3. Surgical and pathological findings

\begin{tabular}{|c|c|}
\hline & $(n=50)$ \\
\hline \multicolumn{2}{|c|}{ Operation time $(\mathrm{min})$} \\
\hline $\begin{array}{l}\text { Median } \\
\text { Range } \\
\text { IQR }\end{array}$ & $\begin{array}{c}150.5 \\
63-373 \\
101-229.3\end{array}$ \\
\hline \multicolumn{2}{|l|}{ Blood loss (ml) } \\
\hline $\begin{array}{l}\text { Median } \\
\text { Range } \\
\text { IQR }\end{array}$ & $\begin{array}{c}50 \\
\text { Little }-2200 \\
\text { Little }-272.5\end{array}$ \\
\hline \multicolumn{2}{|c|}{ Type of gastrectomy } \\
\hline $\begin{array}{l}\text { Partial } \\
\text { Proximal } \\
\text { Total }\end{array}$ & $\begin{array}{c}42(84 \%) \\
5(10 \%) \\
3(6 \%)\end{array}$ \\
\hline \multicolumn{2}{|c|}{ Combined resection of other organs (excluding the gallbladder) } \\
\hline $\begin{array}{l}\text { No } \\
\text { Yes }^{\text {a }} \\
\text { Spleen } \\
\text { Distal pancreas } \\
\text { Transverse colon } \\
\text { Liver }\end{array}$ & $\begin{array}{c}38(76 \%) \\
12(24 \%) \\
9 \\
3 \\
2 \\
2\end{array}$ \\
\hline \multicolumn{2}{|c|}{ Completeness of surgery } \\
\hline $\begin{array}{l}\text { R0 } \\
\text { R1 } \\
\text { R2 }\end{array}$ & $\begin{array}{c}48(96 \%) \\
1(2 \%) \\
1(2 \%)\end{array}$ \\
\hline \multicolumn{2}{|c|}{ Preservation of at least half of the stomach with $\mathrm{RO}$ resection } \\
\hline $\begin{array}{l}\text { Yes } \\
\text { No }\end{array}$ & $\begin{array}{c}42(84 \%) \\
8(16 \%)\end{array}$ \\
\hline \multicolumn{2}{|l|}{ Tumour size $(\mathrm{cm})$} \\
\hline $\begin{array}{l}\text { Median } \\
\text { Range } \\
\text { IQR }\end{array}$ & $\begin{array}{c}8.0 \\
4.7-20.0 \\
7.5-11.8\end{array}$ \\
\hline \multicolumn{2}{|c|}{ Histologically confirmed metastasis } \\
\hline $\begin{array}{l}\text { None } \\
\text { Peritoneum }\end{array}$ & $\begin{array}{c}47(94 \%) \\
3(6 \%)\end{array}$ \\
\hline \multicolumn{2}{|l|}{ Mitotic count } \\
\hline $\begin{array}{l}<5 / 50 \mathrm{HPF} \\
5-9 / 50 \mathrm{HPF} \\
\geqslant 10 / 50 \mathrm{HPF}\end{array}$ & $\begin{array}{c}42(84 \%) \\
3(6 \%) \\
5(10 \%)\end{array}$ \\
\hline
\end{tabular}

A

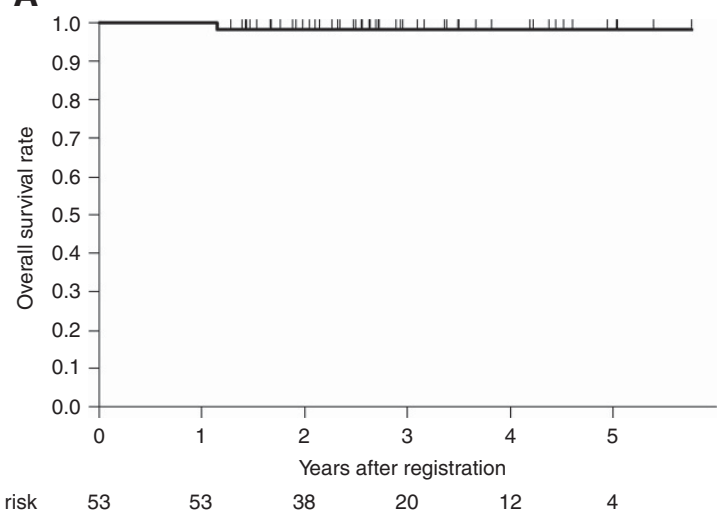

B

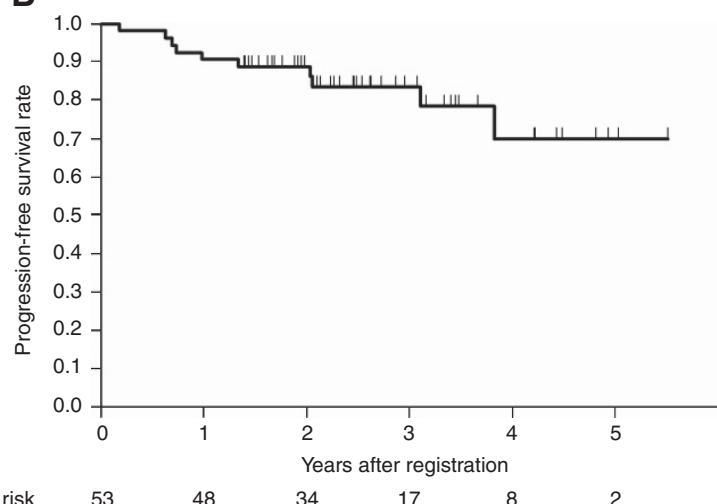

$\begin{array}{lllllll}\text { Number at risk } & 53 & 48 & 34 & 17 & 8 & 2\end{array}$

Figure 3. Kaplan-Meier estimates of (A) overall survival and (B) progression-free survival for 53 patients in the full analysis set.

$12 \mathrm{~cm}$ ), $\sim 80 \%$ of the patients achieved preservation of at least half of the stomach, and only three patients (6\%) underwent total gastrectomy. Our results suggesting that the beneficial effect of neoadjuvant imatinib is inconsistent with the results of a Japanese multi-institutional retrospective study showing that 17 (23\%) of 73 patients with large $(\geqslant 10 \mathrm{~cm})$ gastric GIST required total gastrectomy (Wada et al, 2014). 
The duration of neoadjuvant imatinib administration is important to obtain sufficient response. In a previous phase II study (RTOG0132) patients received neoadjuvant imatinib for only 8-12 weeks (median, 9.9 weeks), and the R0 resection rate was only $68 \%(21 / 31)$ despite the smaller tumour size (median, $8.7 \mathrm{~cm}$ ) compared to our study (Wang et al, 2012). In a previous randomised study of first-line imatinib treatment (B2222) for patients with unresectable or metastatic GISTs, 75\% of patients who achieved PR needed 5.3 months to obtain their response (Blanke et al, 2008). A Japanese phase II study for patients with unresectable or metastatic GIST also revealed that the cumulative response rate reached a plateau after 200 days (Nishida et al, 2008). Based on these results, we judged that 6 months is the minimum duration of neoadjuvant imatinib therapy needed to obtain a certain volume reduction of GISTs. In another phase II study (APOLLON) evaluating the efficacy of neoadjuvant imatinib for 6 months in patients with various types (size, risk classification, tumour location) of potentially resectable GIST, the R0 resection rate was $71 \%(32 / 45)$ (Hohenberger et al, 2012). The R0 resection rate without tumour rupture $(91 \%)$ in our study was higher than that in any other neoadjuvant or adjuvant studies (Hohenberger et al, 2012; McCarter et al, 2012; Wang et al, 2012; Casali et al, 2015), although our study included larger GISTs. Thus, we considered that the main reason for the high $\mathrm{R} 0$ resection rate were the long duration of neoadjuvant imatinib therapy. However, it is important to consider the risk of tumour progression during long treatments, because one patient whose tumour demonstrated a KIT exon 11 mutation showed new peritoneal metastasis on CT after 8 months of neoadjuvant imatinib in spite of high imatinib plasma trough level $(5,284 \mathrm{ng} / \mathrm{ml}$ at 6 months $)$.

This study was originally designed with 2-year progression-free survival rate as the primary end point. In 2012, a phase III study (SSGXVIII/AIO) showed that 3-year adjuvant imatinib improved survival in high-risk GIST patients compared with 1-year adjuvant imatinib (Joensuu et al, 2012). After September 2012, therefore, this study protocol recommended administering adjuvant imatinib for 3 years. This extended treatment duration may have easily affected the initial primary end point of 2-year progression-free survival. Response rate according to RECIST is the most frequently used end point in phase II studies of neoadjuvant treatment for solid tumours, but it may not be appropriate for response evaluation of imatinib for GIST (Benjamin et al, 2007). Thus, the primary end point in this study was changed to R0 resection rate in July 2013 according to the recommendation from the Steering Committees of both the Japanese Study Group on GIST and the Korean GIST Study Group. The prognostic impact of R0 resection in the management of localised GIST has been well recognised (Miettinen and Lasota, 2006b; Dematteo et al, 2008; Joensuu, 2008).

This study has several limitations. First, it was a single-arm nonrandomised study and the follow-up period was short. As many patients developed recurrence after the termination of adjuvant imatinib in previous studies (Corless et al, 2014; Casali et al, 2015; Joensuu et al, 2016), we could not determine the survival benefit of neoadjuvant treatment in this study. Second, subjects were limited to those with GIST of the stomach. Since long-term survival and R0 resection rate strongly depend on GIST location (Dematteo et al, 2008; Joensuu et al, 2012), the selection of only gastric GIST in our study might have contributed to the high $\mathrm{R} 0$ resection rate. GIST of the rectum or duodenum may be a good target population for neoadjuvant imatinib, because preservation of organ function is more critical in these patients. However, evaluation of organ function preservation may differ among organs. Furthermore, small bowel GIST may be associated with KIT exon 9 mutation and may require higher dose imatinib. Future studies are warranted to evaluate the benefit of neoadjuvant imatinib in patients with GIST of other organs. Finally, this study did not require mutation analysis before enrolment, but eventually most cases showed KIT exon 11 mutation, which might have led to the high R0 resection rate. The response of imatinib treatment can be predicted by genotyping (Heinrich et al, 2003; Debiec-Rychter et al, 2006). Indeed, one patient skipped treatment after enrolment in this study and went straight to surgery because PDGFRA exon $18 \mathrm{D} 842 \mathrm{~V}$ mutation was found before the initiation of neoadjuvant imatinib. However, two patients with wild-type GIST underwent neoadjuvant imatinib for 6-9 months without disease progression followed by $\mathrm{R} 0$ resection. Although mutation analysis using biopsy specimens is sometimes difficult or may require much time before results are obtained, we recommend it before starting neoadjuvant imatinib if it is available.

To our knowledge, this phase II study is the only reported multinational prospective study to prove the efficacy of neoadjuvant imatinib administered for 6-9 months in patients with large gastric GIST. We ultimately obtained a much higher R0 resection rate $(91 \%)$ than expected. The toxicity was tolerable, and it did not increase postoperative complications. These findings suggest that neoadjuvant imatinib for 6-9 months would be a promising treatment in patients with high-risk GISTs. Neoadjuvant imatinib may provide certain benefit for patients with GIST small in size and a high mitotic count. However, we cannot obtain accurate mitotic counts using preoperative biopsy specimens due to tumour heterogeneity (Yasui et al, 2006; Nishida et al, 2008). We also think that patients with huge tumour may have more benefit from neoadjuvant treatment than those with small GIST, because shrinkage of tumour size by neoadjuvant imatinib may lead to both prevention of tumour rupture during surgery and preservation of stomach function due to avoiding total gastrectomy. The mitotic count in the resected specimens may have decreased as treatment effect, and could potentially affect subsequent decisionmaking of adjuvant imatinib in clinical practice. Although the lack of reliable mitotic counts may result in overtreatment of some patients, tumour size of $10 \mathrm{~cm}$ or larger seemed to be one of the most useful criterion to determine the indication for neoadjuvant imatinib.

\section{ACKNOWLEDGEMENTS}

In Japan, this study was supported by Non-Profit Organisation of the Research Group for Rare Neoplasms of Japan (Gran-Japan) and the Japanese Study Group on GIST. In South Korea, this study was supported by the Korean GIST Study Group and Novartis. We thank all the patients and clinicians. We also thank Ms. Yuriko Takeda from the SCCRE Data Centre in Osaka University and Ms. Kahee Kim from the Medical Research Collaborating Center in Seoul National University Hospital for data management.

\section{CONFLICT OF INTEREST}

Yukinori Kurokawa has received honoraria from Novartis, Pfizer, and Taiho. Haruhiko Cho has received honoraria from Novartis, Pfizer, and Bayer. Kazuhito Nabeshima has received honoraria from Pfizer. Seiichi Hirota has received honoraria from Novartis. Toshirou Nishida has received honoraria from Novartis, Pfizer, Bayer, and Taiho. Han-Kwang Yang, Min-Hee Ryu, Sook Ryun Park, Hyuk-Joon Lee, Oh Kyoung Kwon, Kyung Hee Lee, SeongHo Kong, Jeong-Hwan Yook, Yuichiro Doki, Seock-Ah Im, Seiichi Hirota, Seokyung Hahn, Toshirou Nishida, and Yoon-Koo Kang have received grant support from Novartis. All other authors declare no competing interests. 


\section{REFERENCES}

Benjamin RS, Choi H, Macapinlac HA, Burgess MA, Patel SR, Chen LL, Podoloff DA, Charnsangavej C (2007) We should desist using RECIST, at least in GIST. J Clin Oncol 25: 1760-1764.

Blanke CD, Demetri GD, von Mehren M, Heinrich MC, Eisenberg B, Fletcher JA, Corless CL, Fletcher CD, Roberts PJ, Heinz D, Wehre E, Nikolova Z, Joensuu H (2008) Long-term results from a randomized phase II trial of standard- versus higher-dose imatinib mesylate for patients with unresectable or metastatic gastrointestinal stromal tumors expressing KIT. J Clin Oncol 26: 620-625.

Casali PG, Le Cesne A, Poveda Velasco A, Kotasek D, Rutkowski P, Hohenberger P, Fumagalli E, Judson IR, Italiano A, Gelderblom H, Adenis A, Hartmann JT, Duffaud F, Goldstein D, Broto JM, Gronchi A, Dei Tos AP, Marréaud S, van der Graaf WT, Zalcberg JR, Litière S, Blay JY (2015) Time to definitive failure to the first tyrosine kinase inhibitor in localized GI stromal tumors treated with imatinib as an adjuvant: A European Organisation for Research and Treatment of Cancer Soft Tissue and Bone Sarcoma Group Intergroup Randomized Trial in Collaboration With the Australasian Gastro-Intestinal Trials Group, UNICANCER, French Sarcoma Group, Italian Sarcoma Group, and Spanish Group for Research on Sarcomas. J Clin Oncol 33: 4276-4283.

Choi H, Charnsangavej C, Faria SC, Macapinlac HA, Burgess MA, Patel SR, Chen LL, Podoloff DA, Benjamin RS (2007) Correlation of computed tomography and positron emission tomography in patients with metastatic gastrointestinal stromal tumor treated at a single institution with imatinib mesylate: proposal of new computed tomography response criteria. J Clin Oncol 25: 1753-1759.

Corless CL, Ballman KV, Antonescu CR, Kolesnikova V, Maki RG, Pisters PW, Blackstein ME, Blanke CD, Demetri GD, Heinrich MC, von Mehren M, Patel S, McCarter MD, Owzar K, DeMatteo RP (2014) Pathologic and molecular features correlate with long-term outcome after adjuvant therapy of resected primary GI stromal tumor: the ACOSOG Z9001 trial. J Clin Oncol 32: 1563-1570.

Debiec-Rychter M, Sciot R, Le Cesne A, Schlemmer M, Hohenberger P, van Oosterom AT, Blay JY, Leyvraz S, Stul M, Casali PG, Zalcberg J, Verweij J, Van Glabbeke M, Hagemeijer A, Judson I, EORTC Soft Tissue and Bone Sarcoma GroupItalian Sarcoma Group, Australasian GastroIntestinal Trials Group (2006) KIT mutations and dose selection for imatinib in patients with advanced gastrointestinal stromal tumours. Eur $J$ Cancer 42: 1093-1103.

Dematteo RP, Ballman KV, Antonescu CR, Maki RG, Pisters PW, Demetri GD, Blackstein ME, Blanke CD, von Mehren M, Brennan MF, Patel S, McCarter MD, Polikoff JA, Tan BR, Owzar K, American College of Surgeons Oncology Group (ACOSOG) Intergroup Adjuvant GIST Study Team (2009) Adjuvant imatinib mesylate after resection of localised, primary gastrointestinal stromal tumour: a randomised, double-blind, placebo-controlled trial. Lancet 373: 1097-1104.

Dematteo RP, Gold JS, Saran L, Gönen M, Liau KH, Maki RG, Singer S, Besmer P, Brennan MF, Antonescu CR (2008) Tumor mitotic rate, size, and location independently predict recurrence after resection of primary gastrointestinal stromal tumor (GIST). Cancer 112: 608-615.

Doyon C, Sidéris L, Leblanc G, Leclerc YE, Boudreau D, Dubé P (2012) Prolonged therapy with imatinib mesylate before surgery for advanced gastrointestinal stromal tumor results of a Phase II trial. Int J Surg Oncol 2012: 761576

Eisenhauer EA, Therasse P, Bogaerts J, Schwartz LH, Sargent D, Ford R, Dancey J, Arbuck S, Gwyther S, Mooney M, Rubinstein L, Shankar L, Dodd L, Kaplan R, Lacombe D, Verweij J (2009) New response evaluation criteria in solid tumours: revised RECIST guideline (version 1.1). Eur $J$ Cancer 45: 228-247.

Heinrich MC, Corless CL, Demetri GD, Blanke CD, von Mehren M, Joensuu H, McGreevey LS, Chen CJ, Van den Abbeele AD, Druker BJ, Kiese B, Eisenberg B, Roberts PJ, Singer S, Fletcher CD, Silberman S, Dimitrijevic S, Fletcher JA (2003) Kinase mutations and imatinib response in patients with metastatic gastrointestinal stromal tumor. J Clin Oncol 21: 4342-4349.

Hirota S, Isozaki K, Moriyama Y, Hashimoto K, Nishida T, Ishiguro S, Kawano K, Hanada M, Kurata A, Takeda M, Muhammad Tunio G, Matsuzawa Y, Kanakura Y, Shinomura Y, Kitamura Y (1998) Gain-offunction mutations of c-kit in human gastrointestinal stromal tumors. Science 279: 577-580.
Hirota S, Ohashi A, Nishida T, Isozaki K, Kinoshita K, Shinomura Y, Kitamura Y (2003) Gain-of-function mutations of platelet-derived growth factor receptor alpha gene in gastrointestinal stromal tumors. Gastroenterology 125: 660-667.

Hohenberger P, Langer C, Wendtner CM, Hohenberger W, Pustowka A, Wardelmann E, Andre E, Licht T (2012) Neoadjuvant treatment of locally advanced GIST: results of APOLLON, a prospective, open label phase II study in KIT- or PDGFRA-positive tumors. J Clin Oncol 30(suppl): abstr 10031.

Joensuu H (2008) Risk stratification of patients diagnosed with gastrointestinal stromal tumor. Hum Pathol 39: 1411-1419.

Joensuu H, Eriksson M, Sundby Hall K, Hartmann JT, Pink D, Schütte J, Ramadori G, Hohenberger P, Duyster J, Al-Batran SE, Schlemmer M, Bauer S, Wardelmann E, Sarlomo-Rikala M, Nilsson B, Sihto H, Monge OR, Bono P, Kallio R, Vehtari A, Leinonen M, Alvegård T, Reichardt P (2012) One vs three years of adjuvant imatinib for operable gastrointestinal stromal tumor: a randomized trial. JAMA 307: $1265-1272$.

Joensuu H, Eriksson M, Sundby Hall K, Reichardt A, Hartmann JT, Pink D, Ramadori G, Hohenberger P, Al-Batran SE, Schlemmer M, Bauer S, Wardelmann E, Nilsson B, Sihto H, Bono P, Kallio R, Junnila J, Alvegård T, Reichardt P (2016) Adjuvant Imatinib for High-Risk GI Stromal Tumor: Analysis of a Randomized Trial. J Clin Oncol 34: 244-250.

Joensuu H, Vehtari A, Riihimäki J, Nishida T, Steigen SE, Brabec P, Plank L, Nilsson B, Cirilli C, Braconi C, Bordoni A, Magnusson MK, Linke Z, Sufliarsky J, Federico M, Jonasson JG, Dei Tos AP, Rutkowski P (2012) Risk of recurrence of gastrointestinal stromal tumour after surgery: an analysis of pooled population-based cohorts. Lancet Oncol 13: 265-274.

McCarter MD, Antonescu CR, Ballman KV, Maki RG, Pisters PW, Demetri GD, Blanke CD, von Mehren M, Brennan MF, McCall L, Ota DM, DeMatteo RP, American College of Surgeons Oncology Group (ACOSOG) Intergroup Adjuvant Gist Study Team (2012) Microscopically positive margins for primary gastrointestinal stromal tumors: analysis of risk factors and tumor recurrence. J Am Coll Surg 215: 53-59.

Miettinen M, Lasota J (2006a) Gastrointestinal stromal tumors: pathology and prognosis at different sites. Semin Diagn Pathol 23: 70-83.

Miettinen M, Lasota J (2006b) Gastrointestinal stromal tumors: review on morphology, molecular pathology, prognosis, and differential diagnosis. Arch Pathol Lab Med 130: 1466-1478.

Nishida T, Hirota S, Yanagisawa A, Sugino Y, Minami M, Yamamura Y, Otani Y, Shimada Y, Takahashi F, Kubota T, GIST Guideline Subcommittee (2008) Clinical practice guidelines for gastrointestinal stromal tumor (GIST) in Japan: English version. Int J Clin Oncol 13: 416-430.

Nishida T, Shirao K, Sawaki A, Koseki M, Okamura T, Ohtsu A, Sugiyama T, Miyakawa K, Hirota S (2008) Efficacy and safety profile of imatinib mesylate (ST1571) in Japanese patients with advanced gastrointestinal stromal tumors: a phase II study (STI571B1202). Int J Clin Oncol 13: 244-251.

Robertson CS, Chung SC, Woods SD, Griffin SM, Raimes SA, Lau JT, Li AK (1994) A prospective randomized trial comparing R1 subtotal gastrectomy with R3 total gastrectomy for antral cancer. Ann Surg 220: 176-182.

Rubin BP, Heinrich MC, Corless CL (2007) Gastrointestinal stromal tumour. Lancet 369: 1731-1741.

Sjölund K, Andersson A, Nilsson E, Nilsson O, Ahlman H, Nilsson B (2010) Downsizing treatment with tyrosine kinase inhibitors in patients with advanced gastrointestinal stromal tumors improved resectability. World J Surg 34: 2090-2097.

Tirumani SH, Shinagare AB, Jagannathan JP, Krajewski KM, Ramaiya NH, Raut CP (2014) Radiologic assessment of earliest, best, and plateau response of gastrointestinal stromal tumors to neoadjuvant imatinib prior to successful surgical resection. Eur J Surg Oncol 40: 420-428.

Wada N, Kurokawa Y, Nishida T, Takahashi T, Toyokawa T, Kusanagi H, Hirota S, Tsujinaka T, Mori M, Doki Y (2014) Subgroups of patients with very large gastrointestinal stromal tumors with distinct prognoses: a multicenter study. J Surg Oncol 109: 67-70.

Wang D, Zhang Q, Blanke CD, Demetri GD, Heinrich MC, Watson JC, Hoffman JP, Okuno S, Kane JM, von Mehren M, Eisenberg BL (2012) Phase II trial of neoadjuvant/adjuvant imatinib mesylate for advanced primary and metastatic/recurrent operable 
gastrointestinal stromal tumors: long-term follow-up results of Radiation Therapy Oncology Group 0132. Ann Surg Oncol 19: 1074-1080.

Yasui H, Konishi E, Urasaki K, Yasukawa S, Yanagisawa A (2006) Intratumoral heterogeneity of MIB-1 labelling index in gastric gastrointestinal stromal tumor (GIST). Gastric Cancer 9: 223-228. (c) (1) (2) This work is licensed under the Creative Commons (By $\mathrm{Nc}$ sA Attribution-Non-Commercial-Share Alike 4.0 International License. To view a copy of this license, visit http:// creativecommons.org/licenses/by-nc-sa/4.0/

(C) The Author(s) named above 2017 